\title{
Estruturas secretoras de Pavonia alnifolia (Malvaceae), uma espécie ameaçada de extinção
}

\section{Secretory structures in Pavonia alnifolia (Malvaceae), an endangered species of extinction}

\author{
Rafael Ribeiro Pimentel ${ }^{1}$, Silvia Rodrigues Machado ${ }^{2} \&$ Joecildo Francisco Rocha $^{3,4}$
}

\begin{abstract}
Resumo
Malvaceae possui grande diversidade morfológica de estruturas secretoras, que por sua vez apresentam importância ecológica e taxonômica. Entretanto até o momento não foram encontrados registros de estudos sobre as estruturas secretoras em Pavonia alnifolia A.St.-Hil., uma espécie ameaçada de extinção, endêmica de restingas do Rio de Janeiro e Espírito Santo. No presente estudo são apresentados dados anatômicos e histoquímicos das estruturas secretoras da referida espécie. O material foi coletado na Restinga da Marambaia - Rio de Janeiro e processado de acordo com técnicas usuais para estudos de anatomia e histoquímica. A análise dos resultados mostrou a presença de canais, cavidades, idioblastos e tricomas secretores de mucilagem; idioblastos de substâncias fenólicas e lipídicas, além de nectários florais. As secreções produzidas por estas estruturas representam um papel potencialmente importante para adaptação da espécie ao ambiente de restinga, estando envolvidas na manutenção de interações com insetos visitantes, o que constitui relevante modelo para realização de estudos experimentais com abordagem ecológica.
\end{abstract}

Palavras-chave: anatomia, estruturas secretoras, restinga, Marambaia, Pavonia.

\begin{abstract}
Malvaceae shows a rich morphological diversity of secretory structures, which are of great ecological and taxonomical relevance. Nonetheless, until the present moment, studies on the secretory structures of the studied species were not found. Pavonia alnifolia A.St.-Hil. is endangered species of extinction with restricted distribution within the restingas of Rio the Janeiro and Espírito Santo, Brazil. The species were collected from the former and usual techniques on plant anatomy and histochemistry were performed. Anatomical and histochemical studies of the secretory structures of Pavonia alnifolia are showed in this work. The presence of external and internal secretory structures of mucilage in many organs, idioblasts of phenolic and lipid substances and floral nectaries what is a very important adaptative survival mechanism of the species in the restinga environment. The secretion produced by nectaries is envolved with maintenance of interations with visiting insects, what constitutes a good model to experimental studies with an ecological approach.
\end{abstract}

Key words: anatomy, histochemistry, secretory structures, Marambaia, Pavonia.

\section{Introdução}

Uma das características de grande importância taxonômica e ecológica nos representantes de Malvaceae é a presença de nectários extraflorais e florais, e de estruturas secretoras de mucilagem, presentes nos órgãos vegetativos e reprodutivos, principalmente tricomas secretores, idioblastos, canais e cavidades (Scott \& Bystrom 1970; Gregory \& Baas 1989; Sawidis
1991, 1998; Rocha et al. 2002; Rocha 2004; Rocha \& Machado 2009).

A mucilagem, secreção de natureza mista constituída principalmente por heteropolissacarídeos ácidos e/ou neutros, proteínas e substâncias fenólicas, apresenta ampla distribuição nos vegetais, formando soluções coloidais que em contato com a água tornam-se viscosas (Priolo de Lufrano \& Caffini 1981; Gregory \& Baas 1989; Roshchina \& Roshchina 1993).

\footnotetext{
${ }^{1}$ Bolsista PROIC/DPPG. Depto. de Botânica da Universidade Federal Rural do Rio de Janeiro. ${ }^{2}$ Universidade Estadual Paulista, Instituto de Biociências, Depto. Botânica, Botucatu, SP, Brasil.

${ }^{3}$ Universidade Federal Rural do Rio de Janeiro, Instituto de Biologia, Depto. Botânica, C.P. 74582, 23890-000, Seropédica, RJ, Brasil.

${ }^{4}$ Autor para correspondência: joecildo@ufrrj.br
} 
Essas substâncias podem desempenhar diferentes funções nas plantas, entre elas, a proteção de estruturas ou órgãos em desenvolvimento, retenção de água, reserva de carboidratos, redução da transpiração, proteção contra radiação dispersando ou refletindo a luz incidente, proteção contra herbivoria, lubrificante do ápice das raízes, como adesivo na dispersão de sementes e na regulação da germinação de sementes (Gregory \& Baas 1989; Fahn 1979; Roshchina \& Roshchina 1993; Clifford et al. 2002; Martini et al. 2003). O néctar apresenta diferentes classes de substâncias químicas e encontra-se relacionado com as interações insetoplanta, comumente envolvido na defesa mutualística e/ou atração de polinizadores (Doak et al. 2007).

Pavonia alnifolia A.St.-Hil., uma espécie de Malvaceae com distribuição restrita as restingas do Rio de Janeiro e Espírito Santo, ocorre em vegetação arbustiva densa (Esteves 2001). Esta espécie é referida por Mello Filho et al. (1992) na lista brasileira de espécies ameaçadas de extinção, enquadrada na categoria "vulnerável (VU)" e por Di Maio \& Silva (2000) na categoria "em perigo (EN)" na lista de espécies ameaçadas de extinção no município do Rio de Janeiro. Esta ameaça aparece destacada no anexo do decreto $\mathrm{n}^{\circ} 41.612$ de 23 de dezembro de 2008 , que dispõe sobre a definição de restingas no estado do Rio de Janeiro e estabelece a tipologia e a caracterização ambiental da vegetação de restinga.

Neste trabalho são descritas as estruturas secretoras presentes em $P$. alnifolia enfocando a organização anatômica e as principais classes de substâncias nelas presentes.

\section{Materiais e Métodos}

O material botânico foi coletado na Restinga da Marambaia-RJ, a qual tem início no município do Rio de Janeiro e estendende-se aos municípios de Itaguaí e Mangaratiba. Parte do material foi herborizado e incluído no Herbário (RBR) do Departamento de Botânica da Universidade Federal Rural do Rio de Janeiro sob o número de registro RBR27707.

Para a descrição anatômica foram utilizadas folhas adultas coletadas do quinto nó, e as secções transversais e longitudinais foram obtidas do terço médio da lâmina foliar e do pecíolo. As estípulas foram retiradas do quinto nó e as secções transversais obtidas das regiões distal, mediana e proximal. As secções transversais e longitudinais do caule foram obtidas no primeiro entrenó. Para análise do nectário foram realizadas secções transversais nas sépalas.
As amostras foram fixadas em FAA 50 (Johansen 1940), desidratadas em série etílica, incluídas em resina hidroxietilmetacrilato (Gerrits 1991) e seccionadas em micrótomo rotativo. As secções $(5-10 \mu \mathrm{m})$ foram coradas em Azul de Toluidina 0,05\% em tampão acetato, $\mathrm{pH}$ 4,3 (O'Brien et al. 1964) e montadas entre lâmina e lamínula com resina sintética (Gerlach 1969).

No preparo de lâminas semipermanentes foram utilizadas amostras de material fresco e amostras fixadas em FAA 50 (Johansen 1940), as quais foram seccionadas com o auxílio do micrótomo de Ranvier. As secções foram clarificadas com hipoclorito de sódio a $20 \%$, neutralizadas em água acética a $1 \%$, lavadas em água destilada, coloradas com azul de astra e safranina (Bukatsch 1972) e montadas entre lâmina e lamínula com glicerina a 50\% (Strasburger 1924).

Para verificar os compostos químicos presentes nos diferentes tipos morfológicos de estruturas secretoras, a natureza das paredes celulares e o reconhecimento de alguns metabólitos celulares foram utilizadas secções de material recém coletado, não fixado e/ou estocado em álcool $70 \%$, as quais foram tratadas com Sudan IV (Johansen 1940) e Sudan black B (Pearse 1980), para lipídeos em geral; cloreto férrico a 10\% (Johansen 1940) e dicromato de potássio 10\% (Gabe 1968), para detectar compostos fenólicos; vermelho de rutênio 0,02\% (Jensen 1962), para substâncias pécticas; reagente de Fehling (Purvis et al. 1964), para açúcares redutores; "aniline blue black" (Fisher 1968), solução de azul mercúrio de bromofenol (Mazia et al. 1953) e "xylidine ponceau" (Cortelazzo \& Vidal 1991), para detecção de proteínas; Lugol (Johansen 1940), para amido; ácido periódico/reagente de Schiff(PAS) (Cortelazzo 1992), para polissacarídeos neutros; ácido acético e ácido clorídrico (Howart \& Horner 1959), para identificação de cristais de oxalato de cálcio; floroglucinol em ácido clorídrico (Sass 1951), para evidenciar paredes lignificadas. Foi aplicado tratamento controle para os testes histoquímicos de acordo com a indicação dos respectivos autores acima citados.

As análises e as fotomicrografias foram feitas com auxílio do microscópio Olympus CH30 e Olympus BX-51, com sistema de captura composto por câmera Q color 5 e software Image-Pro Express.

\section{Resultados}

Tricomas secretores de mucilagem são pluricelulares, localizados em pequenas depressões da epiderme em ambas as superfícies do limbo foliar (Fig. 1a), pecíolo, estípulas (Fig. 1b) e no caule. São 
constituídos por uma célula basal, uma porção intermediária bicelular com paredes laterais fortemente impregnadas por substância lipídica e uma cabeça pluricelular, com parede revestida por cutícula fina (Fig.1 a-b).

Canais e cavidades secretoras de mucilagem, por sua vez, são observados em todo o parênquima cortical e medular do caule (Fig. 1c), do pecíolo (Fig. 1d) e da nervura principal da folha e na sépala. Em secção transversal, apresentam contorno de circular a elíptico, lume conspícuo e epitélio secretor constituído por células de tamanho e forma variadas, com paredes delgadas e pectocelulósicas. Os polissacarídeos que constituem a mucilagem reagem com o corante Azul de Toluidina, formando lamelas concêntricas preenchendo o lume dos canais e das cavidades (Fig. 1d). Secções longitudinais evidenciaram a forma alongada dos canais e que os mesmos apresentam comprimentos diferentes, sendo que os maiores podem ter mais que o dobro do comprimento dos menores, enquanto as cavidades são estruturas mais ou menos isodiamétricas. Canais e cavidades adjacentes podem se fundir formando um grande espaço com forma irregular, o qual fica totalmente preenchido pela mucilagem dificultando, muitas vezes, a classificação dessas duas estruturas.

Idioblastos mucilaginosos ocorrem na epiderme da face adaxial do limbo foliar (Fig. 1e) e no mesofilo (Fig. 1f-g); são conspícuos e apresentam crescimento intrusivo; possuem paredes pectocelulósicas espessas e, em secção transversal, o formato varia de circular a oval. O conteúdo mostrase denso, ocupa todo o protoplasto e cora-se de azul-escuro a roxo pelo Azul de Toluidina. Cristais de oxalato de cálcio do tipo prismático (Fig. 1f) e drusas (Fig. 1g) ocorrem nestes idioblastos.

Os testes histoquímicos revelaram que a mucilagem produzida pelos tricomas secretores, pelos canais, cavidades e pelos idioblastos é constituída por polissacarídeos ácidos e neutros e compostos fenólicos.

Idioblastos fenólicos ocorrem agrupados ou isolados (Fig. 1d,h); encontram-se distribuídos no córtex e medula do pecíolo (Fig. 1d), no mesofilo por entre as células dos parênquimas paliçádico e lacunoso, no córtex da nervura principal da folha e na sépala (Fig. 1h). Na estípula as substâncias fenólicas estão presentes em todas as células da epiderme e do parênquima cortical (Fig. 1b). Já idioblastos de substâncias lipídicas foram revelados por testes histoquímicos entre as células do parênquima lacunoso da estípula.
O nectário floral localiza-se na base do cálice, na face adaxial. Possui coloração amarelada e borda irregularmente ondulada. É constituído por tricomas secretores e por parênquima nectarífero e parênquima subnectarífero (Fig. 1h) vascularizado, predominantemente, por floema.

Os tricomas secretores são multicelulares, claviformes e constituídos por uma célula basal, um pedúnculo curto unisseriado, uma porção bisseriada que por vezes se alarga na porção apical (Fig. 1i). As células apresentam paredes anticlinais espessas, revestidas por cutícula delgada, sendo que nas células do pedúnculo o espessamento é maior e as paredes são impregnadas por substâncias lipídicas; núcleo volumoso; citoplasma denso e vacuoma pouco desenvolvido (Fig. 1i).

O parênquima nectarífero é constituído por vários estratos celulares, cujas células possuem paredes delgadas, com natureza pectocelulósica. Exibe formas e tamanhos variados com arranjo compacto; citoplasma denso (Fig 1h) e núcleo volumoso. O parênquima subnectarífero é constituído por vários estratos celulares, cujas células apresentam dimensões maiores que as do parênquima nectarífero e um maior grau de vacuolização (Fig. 1h). O parênquima subnectarífero é vascularizado predominantemente por floema, o qual pode ser visto em agrupamentos. Grãos de amido e drusas de oxalato de cálcio são vistos em ambos os parênquimas. Idioblastos de substâncias fenólicas ocorrem isolados e/ou em grupos entre as células do parênquima subnectarífero (Fig 1h).

Os testes histoquímicos revelaram a presença de açúcares redutores e proteínas no protoplasto das células dos tricomas e dos parênquimas nectarífero e subnectarífero; substâncias fenólicas no protoplasto das células dos tricomas e dos idioblastos; grãos de amido nas células dos parênquimas nectarífero e subnectarífero; e polissacarídeos no protoplasto das células dos tricomas.

\section{Discussão}

Estruturas secretoras foram registradas ao longo de órgãos vegetativos e reprodutivos de $P$. alnifolia. Os tricomas secretores são observados de forma esparsa em todo o tecido de revestimento de todos os órgãos descritos no presente trabalho. Alguns autores como Ragonese (1960) e Rocha et al. (2002) citam que tricomas secretores são mais comuns em folhas jovens, nas espécies de Malvaceae estudadas pelos mesmos. Entretanto, na espécie aqui estudada, estes tricomas são 
observados não só nas folhas adultas, mas também em todos os outros órgãos e estruturas analisados. Fato esse que se encontra de acordo com autores como Webber (1938) e Inamdar \& Chohan (1969).

O espessamento de natureza lipídica nas paredes laterais das células do pedúnculo dos tricomas secretores de mucilagem de $P$. alnifolia é uma característica comum de tricomas secretores (Fahn 1990, 2000). Tal especialização parece estar relacionada com o controle do fluxo do material secretado através do apoplasto (Schnepf 1969; Shimony et al. 1973), além de promover o isolamento gradual desses tricomas, os quais posteriormente sofrem abscisão.

A distribuição e os aspectos morfológicos dos canais, cavidades e dos idioblastos secretores de mucilagem presentes nos diferentes órgãos de $P$. alnifolia estão, de um modo geral, de acordo com os caracteres descritos para as referidas estruturas em espécies de Hibiscus (Gregory \& Baas 1989; Bakker \& Gerritsen 1992; Bakker \& Baas 1993; Sawidis 1991, 1998; Rocha et al. 2002; Rocha 2004). A presença, o número e a distribuição de canais secretores de mucilagem são referidos como um valioso caráter taxonômico para Malvaceae, tendo sido recentemente utilizado por Rocha \& Neves (2000) e Rocha et al. (2002), como uma das principais características diagnósticas na separação taxonômica de Hibiscus tiliaceus L. e H. pernambucensis Arruda.

Segundo Esau (1974), células mucilaginosas são comuns em algumas famílias de dicotiledôneas, entre elas Malvaceae. Idioblastos mucilaginosos foram descritos por Scott \& Bystrom (1970) em órgãos vegetativos e reprodutivos de Hibiscus esculentus L. Fahn (1985) assinala que, na família Malvaceae, células epidérmicas podem se mostrar mucilaginosas, inclusive na forma de idioblastos. As células, canais e cavidades secretoras de mucilagem constituem uma sinapomorfia para a ordem Malvales (Alverson et al. 1998; Stevens 2001; Judd et al., 2009).

A mucilagem detectada nas diferentes estruturas secretoras de $P$. alifolia é composta por polissacarídeos ácidos e neutros e substâncias fenólicas. Hegnauer (1969 apud Gregory \& Baas 1989) sugere que em Althaea officinalis L. as diferentes frações da mucilagem apresentam funções distintas. A reserva de água é feita pela fração ácida, a qual tem seu pico de produção nos meses do verão e a reserva de carboidratos é feita pela fração neutra, a qual mostra um máximo de produção durante o inverno.
A presença de compostos fenólicos na mucilagem, principalmente taninos, tem importância antimicrobiana e ainda, na proteção contra herbívoros, constituindo uma importante barreira de proteção química (Swain 1979; Carmello et al. 1995).

Levando em consideração a composição química da mucilagem e o habitat de $P$. alnifolia, a presença de mucilagem detectada em diferentes tipos morfológicos de estruturas secretoras contribui para a adaptação potencial da espécie ao ambiente de restinga, bem como na proteção contra herbivoria e patógenos.

As flores de Malvaceae apresentam grande diversidade morfológica e atraem abelhas, vespas, formigas, moscas, mariposas, aves e morcegos, sendo o néctar secretado na superfície interna das sépalas (Judd et al. 2009), o tipo de recompensa que mais comumente as plantas oferecem como recurso alimentar na atração dos polinizadores (Faegri \& Van der Pijl 1980).

Os nectários de $P$. alnifolia localizam-se na base da face interna do cálice sendo constituídos por um grupo de numerosos tricomas secretores e por parênquima nectarífero e subnectarífero. A localização de nectários florais na face interna do cálice, ocupando a porção basal das sépalas, foi relatada por Gunnig \& Hughes (1976), Sawidis et al. (1989), Sawidis (1998), Rocha (2004) para representantes dos gêneros Hibiscus e Abutilon.

$\mathrm{Na}$ interpretação dos resultados relacionados à descrição anatômica dos nectários de $P$. alnifolia foi adotada a denominação parênquimas nectarífero e subnectarífero proposta por Nepi (2007), em substituição a denominação parênquima subglandular adotada tradicionalmente por Durkee (1983), Sawidis (1998), Machado (1999), Rocha et al. (2002) e Rocha (2004).

A presença de tricomas secretores muticelulares e parênquima subglandular foi descrita por Sawidis (1991, 1998), Rocha et al. (2002), Rocha (2004), Rocha \& Machado (2009) para Malvaceae e por Melo et al. (2010) em Fabaceae da caatinga. Nectários florais compostos por tricomas multicelulares, os quais usualmente se unem formando um "carpete" de pêlos e parênquima subglandular é citada por Fahn (2000) e Vogel (2000) como um caráter significativo de Malvaceae e constitui uma sinapomorfia para a família (Alverson et al. 1998; Judd et al. 2009). Segundo Fahn (2000) tais tricomas secretam o néctar pelas células apicais, estando tal característica relacionada com o espessamento de natureza lipídica observado 

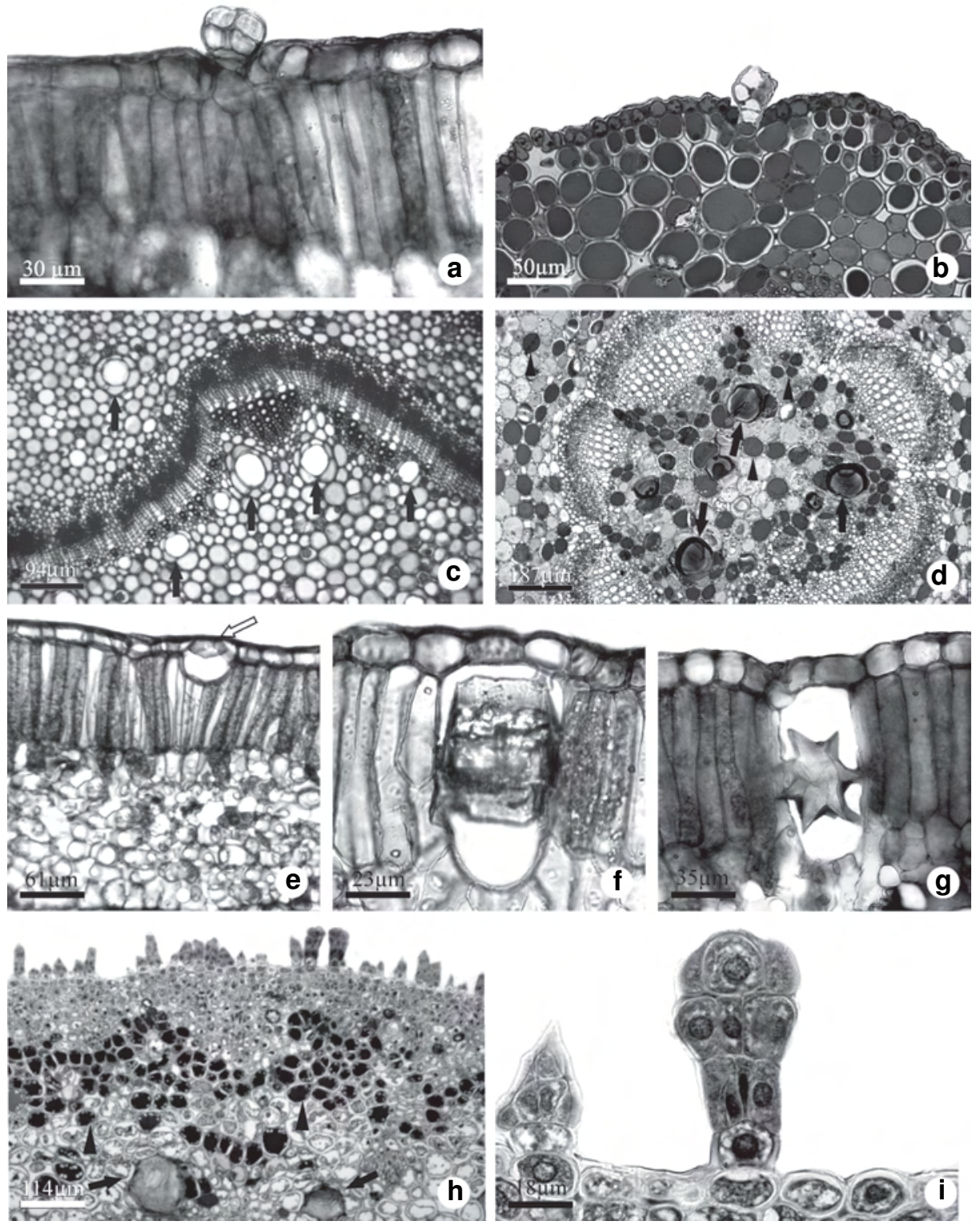

Figura 1 - a-b. Secções transversais da lâmina foliar e estípula - a. tricoma secretor de mucilagem na lâmina foliar; b. tricoma secretor e parênquima cortical rico em substâncias fenólicas na estípula. c. Secção transversal do caule, mostrando canais e cavidades secretores de mucilagem (setas pretas) no córtex e na região perimedular. d. Secção transversal do pecíolo mostrando canais e cavidades secretores de mucilagem (setas pretas) na medula e idioblastos fenólicos (cabeças de seta) no córtex e medula. e-g. Secções transversais da lâmina foliar - e. idioblasto mucilaginoso na face adaxial da epiderme (seta branca); f-g. detalhe idioblastos cristalíferos e mucilaginoso no mesofilo. h. Secção transversal da sépala mostrando vista geral do nectário constituído por tricomas secretores, parênquima nectarífero e subnectarífero onde se observam idioblastos fenólicos (cabeças de seta). Notar cavidades secretoras de mucilagem (setas pretas). i. Detalhe de tricomas secretores do nectário.

Figure 1 - a-b Cross sections of leaf blade and stipule - a. mucilage-secreting trichome on the leaf blade; b. secretory trichome and cortical parenchyma rich in phenolic substances in stipule. c. Cross section of the stem, showing voids secreting mucilage (black arrows) in the cortex and the region perimedullary. d. Cross section of petiole showing voids secreting mucilage (black arrows) in bone and phenolic idioblasts (arrowheads) in the cortex and medulla. e-g. Cross sections of the leaf blade - e. mucilage idioblasts in the adaxial epidermis (white arrow); f-g. detail crystal and mucilage idioblasts in the mesophyll. h. Cross section of sepal showing overview of the nectary consists of secretory trichomes, nectary and subnectary parenchyma where there is phenolic idioblasts (arrowheads). Note mucilage secretory cavities (black arrows). i. Detail of nectary secretory trichomes. 
nas paredes anticlinais das células do pedúnculo dos tricomas, sendo um resultado dos processos de impregnação das paredes anticlinais, similar aos que ocorrem nas células da endoderme. De acordo com Sawidis et al. (1989) tais espessamentos atuam como uma barreira que previne o fluxo apoplástico de substâncias.

Os parênquimas nectaríferos e subnectaríferos apresentam células com arranjo compacto, paredes delgadas, núcleo conspícuo e citoplasma denso, características que segundo Rocha (2004) e Rocha \& Machado (2009), as diferencia das células parenquimáticas adjacentes. Células com estas características foram descritas em diferentes taxa (Sawidis 1998; Machado 1999; Melo et al. 2010) e têm recebido uma atenção especial, visto que estão envolvidas ativamente no processo de descarregamento de açúcares oriundos de fotoassimilados transportados pelo floema, produção e transporte dos precursores do néctar. De acordo com Nepi (2007), as primeiras camadas, compostas por células pequenas de paredes delgadas e citoplasma denso são denominadas de parênquima nectarífero e estão diretamente envolvidas com a produção do néctar, podendo este tecido ser vascularizado por floema. Segundo o mesmo autor, o tecido abaixo do parênquima nectarífero, apresenta feixes vasculares e possui células maiores de citoplasma menos denso e espaços intercelulares maiores, sendo este denominado de parênquima subnectarífero.

Os cristais de oxalato de cálcio observados nas células nectaríferas de $P$. alnifolia são de ocorrência comum em diferentes taxa (Sawidis 1998; Machado 1999; Castro et al. 2001; Paiva et al. 2001; Rocha et al. 2002; Rocha 2004; Paiva \& Machado 2006, 2008; Melo et al. 2010). De acordo com os autores a presença de cristais nas células nectaríferas, provavelmente, está relacionada com processos metabólicos diferenciais de tais células, corroborando com as observações de Böhmker e Koernicke (1917, 1918 apud Arbo 1972) que estabelecem uma possível relação entre a secreção de néctar e a presença de cristais de oxalato de cálcio em células nectaríferas.

Nos nectários florais notam-se feixes vasculares, com predominância de floema, vascularizando o parênquima subnectarífero. Característica semelhante foi relatada para os nectários florais de Hibiscus rosa-sinensis L. por Sawidis et al. (1987a, b) e Sawidis (1998). Segundo Metcalfe \& Chalk (1979), os nectários florais tendem a apresentar vascularização constituída unicamente por floema. A formação de elementos de floema por entre as células secretoras foi também observada por Zer \& Fahn (1992). Segundo Sawidis et al. (1987a) e Frey-Wyssling (1955), há uma correlação positiva entre a quantidade de açúcar no néctar e a quantidade de elementos de floema presentes no nectário. A seiva do floema pode atuar como fonte primária de açúcares essenciais para a composição do néctar (Jian et al. 1997; Machado 1999). Desta forma, pode-se sugerir que a grande quantidade de floema vascularizando o parênquima subnectarífero dos nectários florais internos pode estar associada com a intensa produção de néctar liberado por estes nectários.

Os testes histoquímicos realizados nos nectários detectaram a presença de açúcares redutores, lipídeos, substâncias fenólicas, proteinase polissacarídeos no protoplasto das células. Os constituintes mais comuns do néctar são a sacarose, glicose e frutose. Entretanto, outras substâncias como aminoácidos, proteínas, mucilagens, lipídeos, alcalóides, substâncias fenólicas, terpenóides, glicosídios, ácidos orgânicos, íons minerais, vitaminas, antibióticos e antioxidantes são relatados por diversos autores como fazendo parte da composição do néctar de diferentes taxa (Baker \& Baker 1983a, b, 1990; Roshchina \& Roshchina 1993; Fahn 2000; Stefano et al. 2001; Nicolson \& Thornburg 2007). De acordo com Scogin (1979) e Leitão et al. (2005), o néctar floral e extrafloral de Malvales é composto por maior concentração de glicose e frutose em relação à sacarose, além de apresentar aminoácidos, proteínas e flavonóides.

A presença das diferentes substâncias detectadas no protoplasto das células constituintes do nectário não implica necessariamente que tais substâncias estejam presentes na composição química do néctar, porém que desempenham potenciais funções ecofisiológicas.

Os polissacarídeos presentes nas células dos nectários podem ser de grande valor, não somente nutricional, mas também desempenhar importante função para as estruturas em desenvolvimento, protegendo-as contra a dessecação conforme postulado por Meyberg (1988). Além das referidas funções, a mucilagem pode funcionar na preservação de alguns componentes da secreção exposta na superfície (Machado 1999). Sawidis $(1991,1998)$ ao descrever o tecido subglandular dos nectários de $H$. rosa-sinensis observou a presença de células mucilaginosas e células com óleo. De acordo com o autor, a mucilagem tem importante papel na regulação da economia de água, que é decisiva na secreção do néctar, sendo que o óleo 
protege principalmente os tecidos que contêm açúcares, contra herbivoria. Além da função atribuída pelo referido autor, as substâncias lipídicas provavelmente apresentam grande valor nutricional na dieta dos insetos visitantes (Baker \& Baker 1990). Segundo Machado (1999), os lipídeos detectados nos nectários de Citharexylum mirianthum servem como fonte de energia e/ou de reserva, e ainda podem funcionar na atração ou repelência de visitantes (Rodriguez et al. 1984). As referidas funções podem ser atribuídas aos compostos lipídicos detectados nos idioblastos da estípula, visto que tal apêndice encontra-se envolvido na proteção de gemas e primórdios foliares.

Os compostos fenólicos identificados nas células dos nectários da espécie estudada podem oferecer proteção contra herbívoros, microorganismos, excesso de radiação ultravioleta e ainda, proteger o protoplasto celular mantendo sua integridade quando sujeito ao estresse hídrico (Taiz \& Zeiger 2006; Paiva \& Machado 2008).

A presença de plastídios com grãos de amido em tecidos nectaríferos tem sido extensivamente relatada em literatura (Fahn \& Shimony 2001; Rocha et al. 2002; Rocha 2004; Pacini \& Nepi 2007; Rocha \& Machado 2009). O amido acumulado nos plastídios pode ser a fonte de alguns dos componentes do néctar, pois é total ou parcialmente degradado durante as manifestações da atividade secretora (Durkee et al. 1981; Pacini \& Nepi 2007). É provável que os açúcares redutores detectados nos nectários de $P$. alnifolia sejam resultantes da hidrólise da sacarose oriunda do floema, e/ou da degradação dos grãos de amido presentes nos plastídios.

Em $P$. alnifolia foi registrada uma grande diversidade de estruturas secretoras nos eixos vegetativo e reprodutivo envolvidas na produção de néctar, de mucilagem e compostos fenólicos. Considerando-se que a espécie habita um ambiente com alta incidência de radiação solar e luminosidade, temperaturas elevadas e solos com baixa capacidade de retenção de água e alta salinidade, a presença de estruturas externas e internas secretoras de mucilagem em todos os órgãos da planta em diferentes fases de desenvolvimento representa um importante mecanismo adaptativo e de sobrevivência da espécie aos ambientes de restinga. Na superfície da planta, a mucilagem atua protegendo contra a dessecação e ainda, na proteção contra herbivoria e patógenos. No interior da planta, pode atuar na reserva de água e carboidratos, no balanço hídrico, na resistência contra a seca e devido à presença de compostos fenólicos na secreção, pode reforçar a proteção contra herbívoros e patógenos.

Visto o papel desempenhado pela mucilagem, pelas substâncias fenólicas e pelos nectários, os quais provavelmente estão envolvidos na manutenção de interações com os polinizadores, considera-se que a espécie constitui um bom modelo para realização de estudos experimentais com abordagem ecofisiológica. Os resultados estão de acordo com os dados da literatura, que indicam: a) a presença de canais, cavidades e idioblastos secretores de mucilagem e b) nectários florais compostos por tricomas secretores multicelulares sobre as sépalas, como sinapomorfias que corroboram o estabelecimento respectivamente de Malvales e Malvaceae como grupos monofiléticos.

\section{Agradecimentos}

Ao DPPG/UFRRJ a concessão da Bolsa de Iniciação Científica. Ao Pesquisador do IPJBRJ, Massimo Giuseppe Bovini as sugestões e identificação da espécie. À Fundação Carlos Chagas Filho de Amparo a Pesquisa do Estado do Rio de Janeiro (FAPERJ) o auxílio financeiro para o desenvolvimento de projetos na área de Anatomia Vegetal. Processo n ${ }^{\circ}$ E-26/110.734/2008-INST.

\section{Referências}

Alverson, W.S.; Karol, K.G.; Baum, D.A.; Chase, M.W.; Swensen, S.M.; McCourt, R. \& Systma, K.J. 1998. Circumscription of the Malvales and relationships to other Rosidae: Evidence from rbcL sequence data. American Journal of Botany 85: 876-887.

Arbo, M. M. 1972. Estructura y ontogenia de los nectarios foliares del gênero Byttineria (Sterculiaceae). Darwiniana 17:104-158.

Baker, H.G. \& Baker, I. 1983a. A brief historical review of chemistry of floral nectar. In: Bentley, B \& Elias, T.S. The biology of nectaries. Columbia University Press, New York. Pp.126-152.

Baker, H.G. \& Baker, I. 1983b. Floral nectar sugar constituents in relation to pollinator type. In: Jones, C.E. \& Little, R.J. Handbook of experimental pollinator biology. Scientific and Academic Edition, Van Nostrad Reinhold, New York. Pp.117-141.

Baker, H.G. \& Baker, I. 1990. The predictive value of nectar chemistry to the recognition of pollinator type. Israel Journal of Botany 39:157-166. 
Bakker, M.E\& Baas, P. 1993. Cell walls in oil and mucilage cells. Acta Botanica Neerlandica 42: 133-139.

Bakker, M.E \& Gerritsen, A.F. 1992. The development of mucilage cells in Hibiscus schizopetalus. Acta Botanica Neerlandica 41: 31-42.

Bukatsch, F. 1972. Bemerkungem zur doppel far burng Astrablau-Safranin. Mikrokosmos 6: 255.

Carmello, S.M.; Machado, S.R. \& Gregório, E.A. 1995. Ultrastructural aspects of the secretory duct development in Lithraea molleoides (Vell.) Engl. (Anacardiaceae). Revista Brasileira de Botânica 18: 95-103.

Castro, M.A.; Vega, A.S. \& Mulgura, M.E. 2001. Structure and ultrastructure of leaf and calix glands in Galphimia brasiliensis (Malpighiaceae). American Journal of Botany 88: 1935-1944.

Clifford, S.C.; Arndt, S.K.; Popp, M. \& Jones, H.G. 2002. Mucilages and polysaccharides in Ziziphus species (Rhamnaceae): localization, composition and physiological roles during drought-stress. Journal of Experimental Botany 53: 131-138.

Cortelazzo, A.L. 1992. Detecção e quantificação do amido em cotilédones de Canavalia ensiformis e C. gladiata durante o desenvolvimento inicial da planta. Revista Brasileira de Botânica 15: 157-162.

Cortellazo, A.L. \& Vidal, B.C. 1991. Soybean seed proteins: detection in situ and mobilization during germination. Revista Brasileira de Botânica 14: 27-34.

Diário Oficial do Estado do Rio de Janeiro. 2008. Disponível <https://www.imprensaoficial.rj.gov.br/ DO/PI/24_12_2008\%20PI241208___5 e 6>. Acesso em 20 abr 2010.

Di Maio, F.R. \& Silva, M.B.R. 2000. Espécies ameaçadas de extinção no município do Rio de Janeiro. Secretaria Municipal de Meio Ambiente, Rio de Janeiro. 30p.

Doak, P.; Wagner, D. \& Watson, A. 2007 .Variable extrafloral nectary expression and its consequence in quaking aspen. Canadian Journal of Botany 85: 1-9

Durkee, L.T. 1983. The ultrastructure of floral and extrafloral nectaries. In: Bentley, B. \& Elias, T.S. The biology of nectaries. Columbia University Press, New York. Pp. 1-29.

Durkee, L.T.; Gaal, D.J. \& Reisner, W.H. 1981. The floral and extrafloral nectaries Passiflora. I. The floral nectary. American Journal of Botany 68: 453-462.

Esau, K. 1974. Anatomia das plantas com sementes. Ed. Universidade de São Paulo, São Paulo. 293p.

Esteves, G. L. 2001. O gênero Pavonia Cav. (Malvaceae) na região sudeste do Brasil. Boletim do Instituto de Botânica 15: 125-194.

Faegri, K. \& Van der Pijl, L. 1980. De principles of pollination ecology. $3^{\text {rd }}$ ed. Pergamon Press, New York. 291p.

Fahn, A. 1979. Secretory tissues in plants. Academic Press, London. 302p.
Fahn, A. 1985. Anatomia vegetal. Ediciones Piramide, Madri. 559p.

Fahn, A. 1990. Plant anatomy. $4^{\text {th }}$ ed. ButterworthHeinemann, Oxford. 588p.

Fahn, A. 2000. Structure and function of secretory cells. Advances in Botanical Research 31: 37-75.

Fahn, A. \& Shimony, C. 2001. Nectary structure and ultrastructure of unisexual flowers of Ecballium elaterium (L.) A. Rich. (Cucurbitaceae) and their presumptive pollinators. Annals of Botany 87: 27-33.

Fisher, D. B. 1968. Protein staining of ribboned epon sections for light microscopy. Histochemie 16: 92-96.

Frey-Wissling, A. 1955. The phloem supply to the nectaries. Acta Botanica Neerlandica 4: 358-369.

Gabe, M. 1968. Techniniques histologiques. Masson \& Cie, Paris. 1113p.

Gerlach, D. 1969. Botanische mikrotechnik. Georg Thieme Verlag, Stuttgart. 298p.

Gerrits, P.O. 1991. The application of glycol methacrylate in histotechnology; some fundamental principles. Department of anatomy and embriology. State University of Gröningen, Gröningen. 80p.

Gregory, M. \& Baas, P. 1989. Mucilage cells in dicotyledons. Israel Journal of Botany. 38: 125-174.

Gunning, B.E.S. \& Hughes, J.E. 1976. Quantitative assessment of symplastic transport of pre-nectar into the trichomes of Abutilon nectaries. Australian Journal of Plant Physiology 3: 619-637.

Howart, W.O. \& Horner, L.G.G. 1959. Practical botany for the tropics. University London Press, London. 238p.

Inandar, J. A. \& Chohan, A. J. 1969. Epidermal structure and stomatal development in some Malvaceae and Bombacaceae. Annals of Botany 33: 865-878

Jensen, W.A. 1962. Botanical histochemistry: principles and practice. W.H. Freeman, San Francisco. 408p.

Jian, Z.; Zheng-Hai, H. \& Müller, M. 1997. Ultrastructure of the floral nectary of Arabidopsis thaliana L. prepared from high pressure freezing and freeze substitution. Acta Botanica Sinica 39: 289-295.

Johansen, D.A. 1940. Plant microtechnique. MacGrawHill, New York. 523p.

Judd, W. S.; Campbell, C. S.; Kellogg, E. A.; Stevens, P. F. \& Donoghue, M. J. 2009. Sistemática vegetal: um enfoque filogenético. $3^{\mathrm{a}}$ ed. Artmed, Porto Alegre. 612p.

Leitão, C.A.E.; Meira, R.M.S.A.; Azevedo, A.A.; Araújo, J.M.; Silva, K.L.F. \& Collevatti, R.G. 2005. Anatomy of the floral, bract, and foliar nectaries of Triumfetta semitriloba (Tiliaceae). Canadian Journal of Botany. 83: 279-286.

Machado, S.R. 1999. Estrutura e desenvolvimento de nectários extraflorais de Citharexylum mirianthum Cham. (Verbenaceae). Tese de Livre Docência. Universidade Estadual Paulista, Botucatu.113p.

Martini, M.H.; Lenci, C.G. \& Tavares, D.Q. 2003. Mucilage pockets in cotiledon tissue of Theobroma speciosum. Acta Microscopica 12: 65-69. 
Mazia, D.; Brewer, P.A. \& Alfert, M. 1953. The cytochemistry staining and measurement of protein with mercuric bromophenol blue. Biological Bullletin 104: 57-67.

Metcalfe, C.R. \& Chalk, L. 1979. Anatomy of the dicotyledons. Vol. 1. $2^{\text {nd }}$ ed. Clarendon Press, Oxford. 276p.

Melo, Y.; Machado, S.R. \& Alves, M. 2010. Anatomy of extrafloral nectaries in Fabaceae from dry-seasonal forest in Brazil. Botanical Journal of the Linnean Society. 163: 87-98.

Melo Filho, L.E.; Somner, G.V. \& Peixoto, A.L. 1992. Centuria plantarum brasiliensium extintionis minitata. Sociedade Brasileira de Botânica (SBB), Rio de Janeiro. 175p.

Meyberg, M. 1988. Cytochemistry and ultrastructure of the mucilage secreting trichomes of Nymphoides peltata (Menyanthaceae). Annals of Botany 62: 537-547.

Nepi, M. 2007. Nectary structure and ultrastructure. In: Nicolson, S.W.; Nepi, M. \& Pacini E. Nectaries and nectar. Springer, Dordrecht. Pp. 129-166.

Nicolson, S. W.\& Thornburg, R. W. 2007. Nectar Chemistry. In: Nicolson, S.W; Nepi, M. \& Pacini E. Nectaries and nectar. Springer, Dordrecht. Pp. 215-264.

O’Brien, T.P., Feder, N. \& McCully, M.E. 1964. Polychromatic staining of plant cell walls by toluidine blue. Protoplasma. 59: 368-373.

Pacini, E. \& Nepi, M. 2007. Nectar production and presentation. In: Nicolson, S.W; Nepi, M. \& Pacini, E. Nectaries and nectar. Springer, Dordrecht. Pp. 167-214.

Paiva, E.A.S.; Moraes, H.C.; Isaias, R.M.S.; Rocha, D.M.S. \& Oliveira, P.E. 2001. Occurence and structure of extrafloral nectaries in Pterodon pubescens Benth. and Pterodon polygalaeflorus Benth. (FabaceaePapilionoideae). Pesquisa Agropecuária Brasileira 36: 219-224.

Paiva, E.A.S. \& Machado, S.R. 2006. Ontogênese, anatomia e ultra-estrutura dos nectários extraflorais de Hymenaea stigonocarpa Mart. ex Hayne (FabaceaeCaesalpinioideae). Acta Botanica Brasilica 20: 471-482.

Paiva, E.A.S. \& Machado, S.R. 2008. The floral nectary of Hymenaea stigonocarpa (Fabaceae, Caesalpinioideae): structural aspects during floral development. Annals of Botany 101: 125-133.

Pearse, A.G.E. 1968. Histochemistry: theoretical and applied. Vol. 1. $3^{\text {rd }}$ ed. Churchill Livingstone, Edinburgh. 759p.

Priolo de Lufrano, N. S. \& Caffini, N. O. 1981. Mucílagos foliares de Chorisia H.B.K. (Bombacaceae): análisis fitoquímico e enfoque quimiotaxonômico. Phyton 40: $13-20$.

Purvis, M. J.; Collier, D. C. \& Walls, D. 1964. Laboratory techniques in botany. Butterwoths, London. 371p.

Ragonese, A.M. 1960. Ontogenia de los distintos tipos de tricomas de Hibiscus rosa-sinensis L. (Malvaceae). Darwiniana. 12: 59-66.
Rocha, J.F. \& Neves, L.J. 2000. Anatomia foliar de Hibiscus tiliaceus L. e Hibiscus pernambucensis Arruda (Malvaceae). Rodriguésia 51: 113-132.

Rocha, J.F.; Neves, L.J. \& Pace, L.B. 2002. Estruturas secretoras em folhas de Hibiscus tiliaceus L. e Hibiscus pernambucensis Arruda. Revista Universidade Rural, Série Ciências de Vida 22: 43-55.

Rocha, J.F. 2004. Estruturas secretoras em Hibiscus pernambucensis Arruda (Malvaceae): anatomia, desenvolvimento, histoquímica e ultra-estrutura. Tese de Doutorado. Universidade Estadual Paulista, Botucatu. 110p.

Rocha, J.F. \& Machado, S.R. 2009. Anatomy, ultrastructure and secretion of Hibiscus pernambucensis Arruda (Malvaceae) extrafloral nectary. Revista Brasileira de Botânica 32: 489-498.

Rodriguez, E.; Healey, P.L. \& Mehta, I. 1984. Biology and chemistry of plant trichomes. Plenum, New York. 255p.

Roshchina, V.V. \& Roshchina, V.D. 1993. The excretory fuction of higher plants. Springer-Verlag, Berlin. 314p.

Sass, J.E. 1951. Botanical microtechnique. The Iowa State College Press, Iowa. 228p.

Sawidis, T.H. 1991. A histochemical study of nectaries of Hibiscus rosa-sinensis. Journal of Experimental Botany 24: 1477-1487.

Sawidis, T.H. 1998. The subglandular tissue of Hibiscus rosa-sinensis nectaries. Flora 193:327-335.

Sawidis, T.H.; Eleftheriou, E.P. \& Tsekos, I. 1987a. The floral nectaries of Hibiscus rosa-sinensis I. Development of the secretory hairs. Annals of Botany 59: 643-652.

Sawidis, T.H.; Eleftheriou, E.P. \& Tsekos, I. 1987b. The floral nectaries of Hibiscus rosa-sinensis L II. Plasmodesmatal frequencies. Phyton 27: 155-164.

Sawidis, T.H.; Eleftheriou, E.P. \& Tsekos, I. 1989. The floral nectaries of Hibiscus rosa-sinensis. III. A morphometric and ultrastructural approach. Nordic Journal of Botany 9: 63-71.

Schnepf, E. 1969. Sekretion und Exkretion bei Pflanzen. Protoplasmatol Hanb Protoplasmaforsch 8: 1-181.

Scogin, R. 1979. Nectar constituents in the genus Fremontia (Sterculiaceae): sugars, flavonoids and proteins. Botanical Gazette 140: 29-31.

Scott, F.M. \& Bystrom, B.G. 1970. Mucilaginous idioblasts in Okra, Hibiscuc esculentus L. In: Robson, N.K.B.; Cutler, D.F. \& Gregory, M. News research in plant anatomy. Academic Press, London. Pp.15-24.

Shimony, C.; Fahn, A. \& Reinhold, L. 1973. Ultrastructure and ion gradients in the salt glands of Avicennia marina (Forsk.) Vierh. New Phytologist 72: 27-36.

Stefano, M.; Papini, A.; Andalo, C. \& Brighigna, L. 2001. Ultrastructural aspects of the hypanthial epithelium of Selenicereus grandiflorus (L.) Britton \& Rose (Cactaceae). Flora 196: 194-203. 
Stevens, P.F. 2001 [continuously updated]. Angiosperm phylogeny website. Disponível em <http://www. mobot.org/MOBOT/research/APweb/>. Acesso em 9 jun 2008.

Strasburger, E. 1924. Handbook of practical botany. $8^{\text {th }}$ ed. George Allen e Nonviirn, London. 533p.

Swain, T. 1979. Tannins and lignins. In: Rosenthal, G.A. \&. Jansen, D.H. (eds.). Herbivores: their interactions with secondary plant metabolites. Academic Press, New York. Pp. 657-682.
Taiz, L. \& Zeiger, E. 2006. Plant physiology. $4^{\text {th }}$ ed. Sinauer Associates, Sunderland. 764p.

Vogel, S. 2000. Floral nectaries of the Malvaceae sensu lato - a conspectus. Kurtziana 28: 155-171.

Webber, I.E. 1938. Anatomy of leaf and stem of Gossipyium. Journal of Agricultural Research. 57: 269-286.

Zer, H. \& Fahn, A. 1992. Floral nectaries of Rosmarinus officinalis L. structure, ultrastructure and nectar secretion. Annals of Botany 70: 391-397. 